\title{
ACUTE CHEST SYNDROME IN PREGNANT WOMEN WITH HEMOGLOBIN SC DISEASE
}

\author{
doi: $10.1590 / \mathrm{S} 1807-59322009000900015$
}

Roseli Mieko Yamamoto Nomura, ${ }^{\mathrm{I}}$ Ana Maria Kondo Igai, ${ }^{\mathrm{I}}$ Karine Tosta, ${ }^{\mathrm{I}}$ Guilherme Henrique Hencklain Fonseca, ${ }^{\mathrm{II}}$ Sandra Fatima Menosi Gualandro, ${ }^{\mathrm{II}}$ Marcelo Zugaib ${ }^{\mathrm{I}}$

\section{INTRODUCTION}

Acute chest syndrome (ACS) is a severe pulmonary complication in pregnant women with sickle cell disease (SCD). ${ }^{1-3}$ Between January 1998 and December 2002, ACS occurred in 4 of 286 pregnant women with SCD in Bahrain $(1.2 \%)$, and it was associated with two maternal deaths. ${ }^{4}$ In the United States, 10 pregnant women $(0.06 \%)$ were diagnosed with ACS out of 17,952 deliveries in women with SCD from 2000 to 2003.5 ACS has been attributed to pulmonary vasoocclusion and fat emboli originated from bone marrow infarctions with subsequent hypoventilation. Infectious etiology has also been considered.

The pregnancy outcome for patients with hemoglobin SC disease has been reported to be good to optimal when compared to the outcome of those with homozygous hemoglobin S (Hb SS). ${ }^{6}$ Although most SC patients are mildly affected by clinical events, some of them develop severe complications. We report two cases of severe ACS in pregnant women with hemoglobin SC disease, including maternal and perinatal outcome.

\section{CASE DESCRIPTIONS}

Case 1: A 26-year-old woman, para 1, with hemoglobin SC disease and no prior history of ACS, was admitted at 32 weeks' gestation with preeclampsia and fetal growth restriction. At the gestational age of $325 / 7$ weeks, she presented with sudden onset of hypertonic uterus, abdominal

\footnotetext{
${ }^{\mathrm{I}}$ Department of Obstetrics and Gynecology, Faculdade de Medicina da Universidade de São Paulo - São Paulo/SP, Brazil.

II Department of Hematology, Faculdade de Medicina da Universidade de São Paulo - São Paulo/SP, Brazil.

Email: roseli.nomura@ hotmail.com

Tel: 55113069.6355
}

discomfort, hypotension, and shortness of breath (oxygen saturation 90\%). An emergency cesarean was performed. Placental abruption was detected, and a stillborn weighing 1,630 $\mathrm{g}$ was delivered. The laboratory test results showed hemoglobin electrophoresis of S $51 \%, \mathrm{C} 47.5 \%$, and F $1.5 \%$, hemoglobin $8.4 \mathrm{~g} / \mathrm{dL}$, white blood cell count (WBCC) $34.3 \times 10^{9} / \mathrm{L}$, platelet count $142,000 / \mathrm{mm}^{3}$, alanine aminotransferase (ALT) $35 \mathrm{U} / \mathrm{L}$, aspartate aminotransferase (AST) $54 \mathrm{U} / \mathrm{L}$, total bilirubin $1.5 \mathrm{mg} / \mathrm{dL}$, and lactate dehydrogenase (LDH) $791 \mathrm{U} / \mathrm{L}$. The patient was transferred to the ICU immediately post-cesarean, where examination revealed that the uterus was contracted and without abnormal bleeding. At the fifth hour post-partum, she presented with bradycardia and hypotension. An intravenous infusion of vasoactive drugs and broad-spectrum antibiotics were administered. A red blood cell transfusion was performed. At the eighth hour post-partum, she was hemodynamically unstable, and echocardiography was used to diagnose diffuse hypokinesis of the right ventricle with dilatation of the right chambers. At the tenth hour post-cesarean, she presented with cardiovascular shock, bradycardia, hypotension, and cardiac arrest. The autopsy revealed bone marrow pulmonary emboli.

Case 2: A 29-year-old woman, primigravida, with hemoglobin SC disease and no prior history of ACS, was admitted at $326 / 7$ weeks with vasoocclusive crisis. Oxygen therapy, pain management, and intravenous fluids were provided. The laboratory tests showed hemoglobin electrophoresis of S $48.8 \%, \mathrm{C} 50.3 \%$, and $\mathrm{F} 0.9 \%$, hemoglobin $9.2 \mathrm{~g} / \mathrm{dL}$, WBCC $17.6 \times 10^{9} / \mathrm{L}$, platelet count

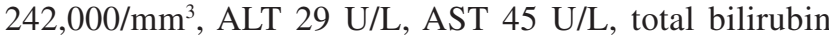
$2.05 \mathrm{mg} / \mathrm{dL}$, and LDH $1325 \mathrm{U} / \mathrm{L}$. At 33 weeks of gestation, the patient presented with sudden onset of dizziness and hypoxemia (oxygen saturation $78 \%$ on room air). Her blood 
pressure was $140 / 90 \mathrm{mmHg}$, heart rate $110 \mathrm{bpm}$, respiratory rate 40 per minute, and temperature $37.2^{\circ} \mathrm{C}$. Her heart sounds were normal, and pulmonary sounds were reduced on lung bases bilaterally. Broad-spectrum antibiotics were administered. A chest X-ray revealed no abnormalities. Cardiotocography showed fetal tachycardia and repeated late decelerations. Fetal distress was diagnosed. At this time, the maternal hemoglobin level was $6.3 \mathrm{~g} / \mathrm{dL}$. Two packs of red blood cells were transfused prior to the emergency cesarean. A small-for-gestational-age male infant was born, weighing 2,020 g, with Apgar scores of 1, 6, and 8 at 1, 5, and 10 minutes, respectively. After the cesarean, the patient was transferred to the ICU and received 3 more units of red blood cell concentrate. She was discharged from the hospital 10 days postpartum, and the newborn was alive and well.

\section{DISCUSSION}

ACS is an important cause of maternal morbidity and mortality, leading to hospital admission of pregnant women with SCD. Early identification of ACS is highly desirable, particularly in pregnant women with SCD. Aggressive treatment and red blood cells transfusions should be instituted before childbirth in order to prevent an adverse outcome for both mother and infant. Maternal acute hypoxemia leads to fetal distress and adverse perinatal outcome. During pregnancy, ACS has been described as presenting favorable maternal and neonatal outcomes. ${ }^{5}$ Recently, ACS during pregnancy has been reported as the initial manifestation of SCD. ${ }^{7}$

The clinical presentation of ACS depends on etiological factors; however, it is not identifiable in almost $46 \%$ of cases. ${ }^{2}$ If the clinical course of the respiratory failure in those patients is not clear, with a worsening of hypoxia and rapid deterioration of the clinical condition, pulmonary embolism should be considered. Treatment would require the use of antibiotics, oxygen therapy, pain control, administration of IV fluids, and red blood cell transfusion or exchange transfusion. The decision-making process with regard to the use of red blood cell or an exchange transfusion should be based upon the severity of maternal and fetal compromise. An early red blood cell transfusion may increase the oxygencarrying capacity and improve pulmonary function in pregnant patients with ACS prior to cesarean delivery.

Female patients with SC disease may present with complications at any time over the course of the pregnancy, labor and delivery, or post-partum. Prompt recognition of severe respiratory failure is required to provide the intensive treatment needed to improve maternal-fetal outcomes. Obstetricians must work closely with hematologists in order to prevent maternal death in cases of ACS during pregnancy.

\section{REFERENCES}

1. Maitre B, Habibi A, Roudot-Thoraval F Bachir D, Belghiti DD, et al. Acute chest syndrome in adults with sickle cell disease. Chest. 2000;117:1386-92.

2. Vichinsky EP, Neumayr LD, Earles AN, Williams R, Lennette ET, Dean $\mathrm{D}$, et al. Causes and outcomes of the acute chest syndrome in sickle cell disease: National Acute Chest Syndrome Study Group. N Engl J Med. 2000;342:1855-65.

3. Elsayegh D, Shapiro JM. Sickle cell vasoocclusive crisis and acute chest syndrome at term pregnancy. Southern Med J. 2007;100:77-9.

4. Rajab KE, Issa AA, Mohammed AM, Ajami AA. Sickle cell disease and pregnancy in Bahrain. Int J Gynecol Obstet. 2006;93:171-5.
5. Villers MS, Jamison MG, De Castro LM, James AH. Morbidity associated with sickle cell disease in pregnancy. Am J Obstet Gynecol 2008;199:125.e1-125.e5.

6. Serjeant GR, Hambleton I, Thame M. Fecundity and pregnancy outcome in a cohort with sickle cell-haemoglobin C disease followed from birth. BJOG. 2005;112:1308-14.

7. Campbell K, Ali U, Bahtiyar M. Acute chest syndrome during pregnancy as initial presentation of sickle cell disease: a case report. Am J Perinatol. 2008;25:547-9. 